\title{
Blood loss of scalpel versus cutting cautery in bilateral reduction mammoplasty procedures
}

\author{
Lawrence N Hurst MD FRCSC, Sanjeev Kaila BScPharm \\ Department of Plastic and Reconstructive Surgery, London Health Sciences Centre, \\ London, Ontario
}

LN Hurst, S Kaila. Blood loss of scalpel versus cutting cautery in bilateral reduction mammoplasty procedures. Can J Plast Surg 1996;4(4):195-197. Cutting electrocautery may be used for the dissection of breast tissue in bilateral reduction mammoplasty procedures without adverse effects on wound healing. It has been suggested that the use of cutting cautery reduces perioperative blood loss; however, very few studies have been performed to verify this assumption. This study compares the blood loss using cutting cautery with scalpel dissection. The study analyzed the preoperative and one-day postoperative hemoglobin levels of 22 randomly chosen patients dissected with scalpel at University Hospital during 1983, and compared these results with results obtained from 39 randomly chosen patients dissected using cutting cautery in 1993. The results show a difference in the mean postoperative result of 5.77 $\mathrm{g} / \mathrm{L}$, which is significant at the $95 \%$ confidence level with $\mathrm{P}>0.03$ and $\mathrm{P}<0.04$.

Key Words: Breast reductions, Cutting cautery, Electrocautery, Mammoplasty, Postoperative blood loss

Comparaison des pertes sanguines liées à l'utilisation du scalpel et du cautère lors de réductions mammaires bilatérales

RÉSUMÉ : L'électrocautère peut être utilisé pour la dissection des tissus mammaires lors de réductions mammaires bilatérales, sans réactions indésirables sur la cicatrisation des plaies. Le recours à l'électrocautère réduirait la quantité des pertes sanguines peropératoires, mais très peu d'études ont été menées pour confirmer cette hypothèse. La présente étude visait à comparer les pertes sanguines subies lors de l'emploi de l'électrocautère et du scalpel. L'étude a analysé les taux d'hémoglobine en pré-opératoire et le lendemain de la chirurgie chez 22 patientes choisies aléatoirement ayant subi une dissection au scalpel à l'hôpital universitaire en 1983, comparativement à ceux de 39 patientes choisies aléatoirement ayant subi une dissection à l'électrocautère en 1993. Selon les conclusions de l'étude, on note une différence de l'ordre de 5,77 g/L quant aux résultats postopératoires moyens, ce qui est significatif compte tenu d'un intervalle de confiance de $95 \%$, avec des valeurs $\mathrm{P}>0,03$ et $\mathrm{P}<0,04$. 
Cutting electrocautery has been used in bilateral reduction mammoplasties for the dissection of subcutaneous breast tissue. The rationale for the use of this rather than scalpel dissection is based on the assumption that the microvasculature is instantly cauterized as the tissue is being cut, hence minimizing time needed to obtain hemostasis and minimizing operative blood loss. Although this technique of dissection has been available for some time, there has been no verification of this assumption in the literature to this date. This study compares the two techniques to determine whether there is a reduction in blood loss with cutting cautery versus scalpel dissection. Postoperative hemoglobin levels are used as an estimate of blood loss, and the means of two groups are compared.

Before this technique was adopted, a pilot project was performed to compare the two techniques. In consenting patients, one breast was operated on using normal scalpel dissection. The contralateral breast was operated on using cutting cautery for dissection. In both cases, the skin was incised with a normal scalpel.

There was no difference between the two methods in healing or complications including wound problems, fat necrosis, scars or patient discomfort.

\section{METHODS}

The study was performed by retrospective analysis of two groups of patients undergoing bilateral reduction mammoplasty procedures. A random selection of all patients operated on in two treatment years was obtained from the medical records department of the hospital. The years selected were 1983, when scalpel dissection was used, and 1993, when cutting cautery dissection was used. Both treatment groups underwent a modified inferior flap reduction mammoplasty with pedicled nipple, developed by Hurst (3).

This procedure essentially consists of a de-epithelialized dermal pedicle as an extension of the inferior flap. The bases of the inferior flap then consist of a superiorly curving incision, maintaining vascular supply and cutaneous nerve sensation from the fourth and fifth intercostal nerves.

The first group consisted of 22 patients undergoing bilateral reduction mammoplasties performed in 1983 at University Hospital. These patients were all treated with scalpel dissection of the breast tissue. The preoperative and one-day postoperative hemoglobin levels were noted for each patient. The mean and standard deviation of the postoperative results were then obtained.

The second group consisted of 39 patients on whom bilateral reduction mammoplasties were performed in 1993 at University Hospital. During this year, dissection of the breast tissue was carried out by cutting cautery as opposed to scalpel, again using a similar inferior flap technique. Measurements of preoperative and one-day postoperative hemoglobin levels were obtained. The mean and standard deviations were then also obtained. 


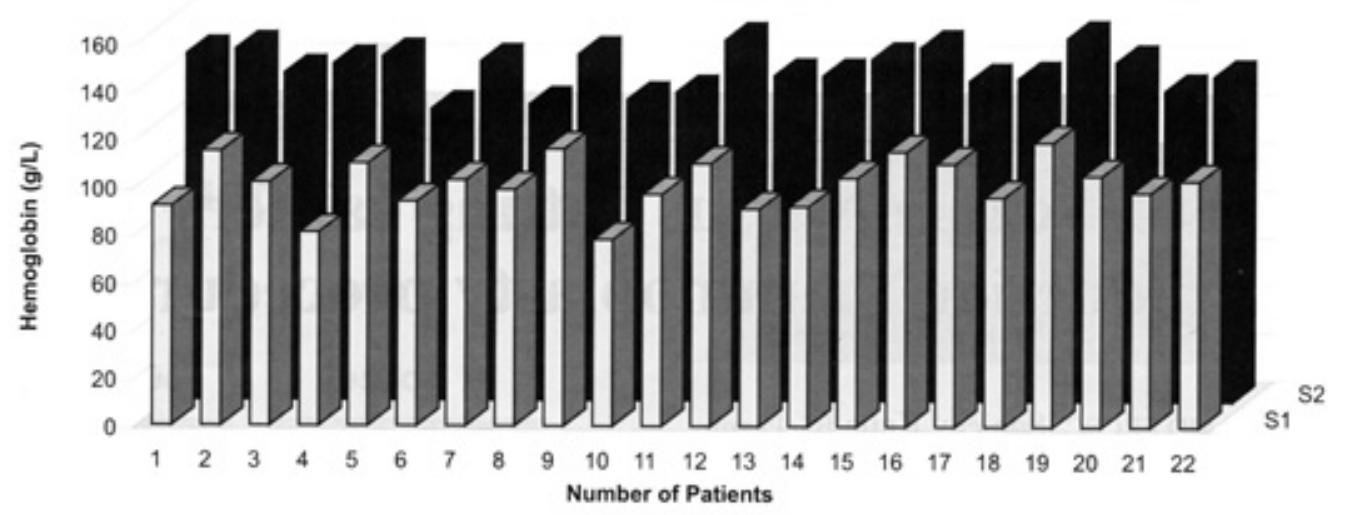

Figure 1) Comparison of preoperative and postoperoative hemoglobin with scalpel (1983). Black bars Postoperative hemoglobin levels; White bars Preoperative hemoglobin levels. S1 Series 1; S2 Series 2

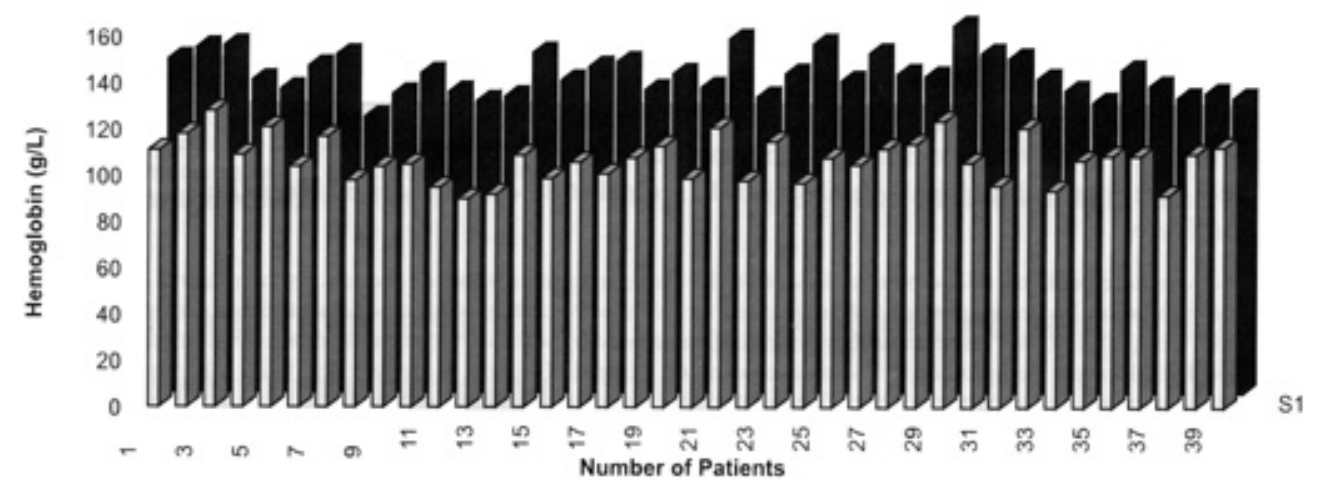

Figure 2) Comparison of preoperative versus and postoperative hemoglobin with electrocautery (1993). Black bars Postoperative hemoglobin levels; White bars Preoperative hemoglobin levels. S1 Series 1

Once these statistical parameters were obtained for both groups, the null hypothesis was created, assuming there was no difference between the two treatment groups, and tested using a simple Student's $t$ test. The distribution of the data was assumed to be normal and the variances unknown. Hence, initially a variance test was performed to determine whether the variances of the two groups of data were similar (1). Once they were determined as similar, a pooled standard deviation was obtained from the following formula for equation 1 :

$$
S_{p}{ }^{2}=\left\{\left(n_{1}-1\right) s_{1}{ }^{2}+\left(n_{2}-1\right) s_{2}{ }^{2}\right\} /\left(n_{1}+n_{2}-2\right)(1)(2)
$$

Once pooled standard deviations were calculated, Student's $t$ values were obtained using the following formula for equation 2 : 


$$
t=\frac{\left\{\left(x_{1}-x_{2}\right) \quad\left(u_{1} \quad u_{2}\right)\right\}}{\sqrt{S_{p}^{2} \div n_{1}+S_{p}^{2} \div n_{2}}}(1,2)
$$

Resultant $t$ values were then compared with a table of critical $t$ values (2) to find the level of significance.

Subsequently, the power of the study was calculated using equation 3 :

$$
n>2\left\{\left(\begin{array}{ll}
z_{2 a} & z_{2 \beta}
\end{array}\right) S_{p}\right\}^{2} \div G^{2}(2)
$$

wthe tabulated $\mathrm{z}$ value for the two-sided distribution at the alpha level preselected; here $\mathrm{n}$ equals sample size of one group, $z_{2 \tilde{a}}$ equals zpower of the study; $S_{p}$ equals the sample pooled population standard deviation; $2 \beta$ equals the tabulated $\mathrm{z}$ value with respect to the and $\mathrm{G}$ equals the difference between the two population means.

\section{RESULTS}

The preoperative and postoperative hemoglobin values are graphed (Figures 1,2). The mean postoperative hemoglobin level for the 22 patients treated with scalpel dissection was $101.36 \mathrm{~g} / \mathrm{L}$ with a standard deviation of $\pm 10.931 \mathrm{~g} / \mathrm{L}$. The corresponding mean hemoglobin value for the 39 electrocautery treated group in 1993 was $107.13 \mathrm{~g} / \mathrm{L}$ with a standard deviation of $\pm 9.362 \mathrm{~g} / \mathrm{L}$ (Table 1).

There remains a difference in the means of $5.77 \mathrm{~g} / \mathrm{L}$. The question of concern is whether this difference is of statistical significance, at the $95 \%$ confidence level. The calculated $t$ value from equation 2 gives a result of 2.16 which compared with the tabulated values (1) is critical between the $96 \%$ and $97 \%$ confidence intervals, with critical values of 2.099 and 2.223 for the given degrees of freedom, respectively. This difference is significant with $0.03<\mathrm{P}<0.04$. Hence at this level of confidence, one must reject the null hypothesis and assume that there is a difference between the two groups of patients.

Results for calculation of power reveal values of $61.41 \%$ with the given confidence level of $95 \%$ (Table 1). 
TABLE 1: Statistical analysis of scalpel versus electrocautery

\begin{tabular}{|l|c|c|}
\hline \multicolumn{1}{|c|}{} & \multicolumn{2}{|c|}{ Postoperative hemoglobin levels } \\
\hline \hline & Scalpel (1983) & Electrocautery \\
\hline Mean $(\mathrm{g} / \mathrm{L})$ & 101.4 & 107.1 \\
\hline $\begin{array}{l}\text { Sample standard } \\
\text { deviation }(\mathrm{g} / \mathrm{L})\end{array}$ & 10.9 & 9.5 \\
\hline Number of Patients & 22 & 39 \\
\hline Variance testing & Variance ratio & Critical value \\
\hline \hline & 0.755 & $\begin{array}{l}1.960 \text { at } 97.5 \text { percentile of normal } \\
\text { distribution }\end{array}$ \\
\hline Pooled standard \\
deviation $(\mathrm{g} / \mathrm{L})$
\end{tabular}

\section{DISCUSSION}

A difference of $5.77 \mathrm{~g} / \mathrm{L}$ in the mean values for hemoglobin concentration was obtained, and statistical analysis excluded the null hypothesis at the $95 \%$ confidence level. Hence the results of this study verify the assumption that the use of cutting cautery reduces blood loss compared with scalpel use.

Aside from statistical significance, these results have practical implications. Concern over the safety of the blood supply has risen dramatically over the past 10 years. Although more strict screening and testing procedures have been implemented, risks remain for any transfusion. Surgeons are more reluctant to use blood transfusions and patients are far more anxious about receiving them. The reduction in blood loss by the use of cutting cautery is an advantage gained by this technique.

\section{REFERENCES}

1. Altman DE. Practical Statistics for Medical Research. New York: Chapman and Hall, 1991.

2. Armitage P, Berry G. Statistical Methods in Medical Research, 3rd edn. London:

Blackwell Scientific Publications, 1994.

3. Hurst LN. Inferior flap reduction mammoplasty with pedicled nipple. Ann Plastic Surg 1983;10:483-7. 